ISSN: 0213-2079

DOI: http://dx.doi.org/10.14201/shhmo201335201235

\title{
CAMPILLO Y ENSENADA: EL SUMINISTRO DE VESTUARIOS PARA EL EJÉRCITO DURANTE LAS CAMPAÑAS DE ITALIA (1741-1748)"
}

\section{Campillo and Ensenada: Supplying Wardrobe for the Army during the Italian Campaigns (1741-1748)}

\section{Sergio SOLBES FERRI}

Universidad de Las Palmas de Gran Canaria

Correo-e: ssolbes@dch.ulpgc.es

RESUMEN: En nuestro estudio analizamos la contratación de vestuario para el ejército español durante el período 1741-1748. Se trata de una etapa de especial actividad bélica coincidente con la campaña desarrollada en Italia, que llegó a movilizar a cerca de 60.000 hombres. Incluye el tiempo de gestión desarrollado por Campillo hasta su muerte y la primera etapa de gobierno de Ensenada hasta la firma de la paz de Aquisgrán. Nuestra documentación se funda en la actividad de la Tesorería General como institución encargada de la financiación de las compras. Podremos comprobar que la fórmula predominante de contratación es el recurso a asentistas, aunque se mantienen otras fórmulas de provisión mejor consideradas por la Corona. Destacaremos la necesidad de diferenciar la presión ejercida sobre los arrendadores de rentas, frente al recurso ineludible a asentistas de provisión; estos últimos mantuvieron inalterados sus contactos con la Real Hacienda durante el período estudiado.

Palabras clave: España siglo XviII, ejército, vestuario, asentistas, Tesorería General.

Nuestro objetivo, con una cronología más amplia que pudiera llegar a abarcar todo el siglo XVIII, se enmarca en el Proyecto de Investigación HAR 2011-23570 (Gobierno de España-MICINN): Movilización de recursos para la guerra y la construcción del Estado en el siglo XVIII: España y su contexto europeo. 
ABSTRACT: The objective of this study is to analyze the contracting of wardrobe for the Spanish Army during the period 1741-1748. This is a time of military activity coincided with the campaign in Italy which came to mobilize about 60,000 men. It includes the management developed by Campillo until his death and the first stage of Ensenada government until the signing of the Treaty of Aquisgran. Our documentation is based on the activity of the General Treasury as an institution responsible for financing purchases. We will see that the main formula is hiring suppliers but still remain other formulas better considered by the Crown. We will emphasize the necessity to differentiate between the pressure exerted over income lessors and provisioning suppliers. These suppliers maintained their positions unchanged during our study period.

Key words: Spain $18^{\text {th }}$ century, Army, Wardrobe, Suppliers, General Treasury.

\section{INTRODUCCIÓN: LA NECESIDAD DE MANTENER A LA TROPA}

El Ejército español del siglo xviII debía ser vestido y armado por cuenta del Rey. Atrás quedó el tiempo de la formación de unidades por parte de la nobleza y también aquel en que la patente real recibida por un capitán para reclutar y formar compañías podía incluir dicha obligación. La restructuración de las tropas borbónicas en la guerra de Sucesión modificó este como otros tantos aspectos organizativos, dentro de un proceso de transición marcado por una inicial dependencia de la ayuda francesa que la nueva Monarquía procuraría muy pronto rechazar ${ }^{1}$. La Real Hacienda debía asumir la financiación completa de los gastos de sus fuerzas armadas y se dispuso a hacerlo. La cuestión no era el qué, sino el cómo hacerlo, a quién recurrir: el grave dilema entre producir o comprar que se mantendrá durante todo el siglo². La solución habitual fue ponerse en manos de

1. No ha sido hasta ahora la cuestión del vestuario de los ejércitos un tema prioritario para la historiografía. Tan solo hemos encontrado una referencia directa en Ozanam, D.: Historia de España Menéndez Pidal. J. M. ${ }^{\mathrm{a}}$ Jover Zamora (dir.). T. XXIX: La época de los primeros Borbones, 1, 17001759,1985 , pp. 562-64. Noticias complementarias sobre la financiación de los ejércitos durante el conflicto sucesorio en KAMEN, La Guerra de Sucesión en España, 1700-1715. Grijalbo, Barcelona, 1974, pp. 75-83; AQUERRETA GONZÁlEZ, S.: «La participación de los financieros nacionales en la Guerra de Sucesión: el abastecimiento de víveres al Ejército» en Torres SÁnCHEz, R. (coord.): Capitalismo mercantil en la España del siglo XVIII. EUNSA, Pamplona, 2000, pp. 273-314; ANDÚJAR CASTILlO, F.: «La reforma militar en el reinado de Felipe V» en Pereira Iglesias, J. L. (coord.): Felipe de Borbón, 1701-1743. Córdoba, 2002, pp. 615-640. Un análisis más general en Gómez Ruíz, M. y Alonso JuANOlA, V.: El Ejército de los Borbones: reinados de Felipe V y Luis I (1700-1746). Madrid, 1989.

2. GonZÁlez EnCISO, A.: «La promoción industrial en la España Moderna: intervención pública e iniciativa privada», y TORRES SÁNCHEZ, R.: «Producir o comprar. La demanda de la Corona española 
grupos privados de asentistas para encargarles de la provisión del suministro ${ }^{3}$. Pero las dudas y rectificaciones entre esta y otras fórmulas alternativas subsistirán. Como tendremos ocasión de comprobar, parece que no se acertó a dar en todo el siglo con un sistema que resultara completamente satisfactorio para las partes implicadas.

Vamos a tratar de exponer en este artículo cómo se gestionó la contratación del vestuario de los ejércitos españoles en un período concreto que abarca desde el ascenso de Campillo a la cúspide de la administración española, en febrero de 1741, hasta el final del período bélico que concluye con la paz de Aquisgrán signada en octubre de 1748. Se trata de una coyuntura dominada por la actuación directa de dos importantes personalidades de la historia de la administración española que, quizá con los precedentes de Alberoni y Patiño, van a marcar las líneas a seguir dentro del proceso de construcción de la nueva Monarquía borbónica durante la segunda mitad del XVIII ${ }^{4}$. Es el tiempo de nuestro análisis una etapa bélica, como casi todo el reinado de Felipe V, situada dentro del contexto de la guerra de la Oreja de Jenkins y la guerra de Sucesión de Austria, que en nuestro caso viene marcada por las campañas de Italia, mucho más que por las batallas navales contra Gran Bretaña, que provocan las salidas masivas de ejércitos expedicionarios. En el año 1731 partió el primero de ellos con el objetivo de ocupar los ducados de Toscana, Parama y Güastalla; en 1734-36 salió el segundo hacia la conquista de Nápoles y Sicilia y, finalmente, las campañas del período 1742-48 en la Saboya-Piamonte e

de productos industriales en el siglo xviI», ambos trabajos en Ribot García, L. A. y De Rosa, L. (dirs.): Industria y Época Moderna. Actas, Madrid, 2000, pp. 15-46 y 95-132.

3. Torres SÁnCHEZ, R.: «Servir al Rey, más una comisión: el fortalecimiento de los asentistas en la Corona Española durante la segunda mitad del siglo XviII» en Mestre SANChís, A.: FernándeZ Albadalejo, P. y Giménez López, E. (coords.): Monarquí, Imperio y pueblos en la España Moderna. Vol. 1, Alicante, 1997, pp. 149-168; y «Cuando las reglas de juego cambian. Mercados y privilegio en el abastecimiento del Ejército español en el siglo XviII», Revista de Historia Moderna 20 (2002), pp. 487-512. También GonZÁlez EnCiso, A.: «Las finanzas reales y los hombres de negocios en el siglo XVIII» en DUBET, A. (coord.): Administrer les finances royales dans la monarchie espagnole (XVIe-XIXe siècles). Presses Universitaires de Rennes, Rennes, 2008, pp. 227-241.

4. Don José del Campillo y Cossío aparece como una figura algo difusa en la historiografía nacional que viene reclamando sin duda mejor suerte. Tan solo Delgado Barrado se ha ocupado exhaustivamente de sus escritos sobre las necesarias reformas económicas como puede verse, entre otros, en Delgado Barrado, J. M.: Aquiles y Teseos. Bosquejos del reformismo borbónico, 1701-1759. Universidad de Granada, Granada, 2007. Mucho más amplio es el número de trabajos referidos al marqués de la Ensenada, aunque fundamentalmente centrados en el famoso Catastro o las causas de su caída en desgracia, así que resultan igualmente escasas las referencias a su actuación en el ámbito castrense. Es obligada la referencia a ANDÚJAR CASTILlo, F.: «La "reforma" militar del Marqués de la Ensenada» en Guimerá Ravina, A. y Peralta Ruíz, V. (coords.): El equilibrio de los imperios: de Utrecht y Trafalgar. Vol. 2, Madrid, 2005, pp. 519-536 junto con las obras más generales RODRíGUEZ Villa, A.: Don Zenón de Somodevilla, marqués de la Ensenada. Ensayo biográfico. Madrid, 1878 y Gómez URdÁnEZ, J. L.: El proyecto reformista de Ensenada. Editorial Milenio, Lleida, 1996. 
Italia central parten con la misión de conservar las conquistas anteriores y tratar de ampliarlas, si ello fuera posible ${ }^{5}$. Este último ejército expedicionario partirá del puerto de Barcelona en febrero de 1742 dividido en dos cuerpos: el primero, al mando del duque de Montemar, desembarcaría en la Toscana para dirigirse hacia el Sur mientras el otro cuerpo, al mando del infante don Felipe y el conde de Glimes, se dirigiría a través de Francia hasta Niza y la Saboya para atacar desde allí el Milanesado. El cuerpo expedicionario de 1734 estuvo formado por 30.000 hombres; en 1742 fueron 40.000 hombres los desembarcados en la Italia Central a los que se unirían los 20.000 hombres trasladados a través de Francia hacia Saboya y el Piamonte; en 1747 solo quedaban 33.000 hombres en Italia porque 40.000 ya habrían vuelto a España. La operación evoluciona hasta convertirse en una serie sucesiva de campañas contra los austríacos de la emperatriz María Teresa y los sardos de Carlos Manuel III que, a la postre, alterarían en muy escasa medida la situación política heredada.

No tenemos intención de ocuparnos del desarrollo de la campaña, sino de observar las circunstancias que afectan al cumplimiento de uno más entre las obligaciones fundamentales que la Monarquía debe acometer para gestionar con éxito dicha campaña junto con armamento, alojamiento y comida; transportes terrestres y marítimos ${ }^{6}$. Trataremos de conocer los sistemas que la Corona utilizó para contratar y pagar proveedores basándonos en dos secciones documentales

5. Un completo y exhaustivo análisis en González EnCiso, A.: «La guerra de la Oreja de Jenkins. Política y economía» en Díaz Benítez, J. J.; Galván Rodríguez, E. y Luxán Meléndez, S. de: Conflictos bélicos y relaciones internacionales (1739-1927). Ediciones Idea, Santa Cruz de Tenerife, 2011, pp. 29-87.

6. La publicación de la obra de Caro Baroja, J.: La Hora Navarra Del XVIII: (Personas, Familias, Negocios e Ideas). Institución Príncipe de Viana, Pamplona, 1985, inició una corriente de atención al suministro de los ejércitos por parte de diversos asentistas navarros que ha mantenido posteriormente su continuidad. Son muchas y muy diversas las publicaciones en artículos, monografías u obras conjuntas que nos ofrecen un panorama muy completo del mundo de los asentistas navarros en el siglo XVIII, aunque hay que constatar que la provisión del vestuario es un sector marginal en dicho análisis porque nunca fue provisto por ellos. Una selección de los principales textos podría ser la siguiente: RODRíGUEZ GARRAZA, R.: «Asentistas navarros durante la Guerra de Sucesión (17051711)», en Enciso Recio, L. M.: La burguesía española en la Edad Moderna. Vol. II, Universidad de Valladolid, Valladolid, 1996, pp. 725-752; AquerreTA, S.: «La Casa de Arizcun 1725-1742: las estrategias financieras de un hombre de negocios en el Madrid de la Ilustración» en SERRANO MARTín, E.; Sarasa Sánchez, E. y Ferrer Benimeli, J. A. (dirs.): El Conde de Aranda y su tiempo. Vol. 1, Institución Fernando el Católico, Madrid, 2000, pp. 659-678; AquerretA, S.: Negocios y finanzas en el siglo XVIII: la familia Goyeneche. EUNSA, Pamplona, 2001; AQUERRETA, S. (coord.): Francisco Mendinueta: finanzas y mecenazgo en la España del siglo XVIII. EUNSA, Pamplona, 2002; HeRNÁNDEZ EsCAYOlA, M. ${ }^{a}$ C.: Negocio y servicio: finanzas públicas y hombres de negocios en Navarra en la primera mitad del siglo XVIII. EUNSA, Pamplona, 2004. GonZALEZ EnCISO, A. (coord.): Navarros en la Monarquía Española en el siglo XVIII. EUNSA, Pamplona, 2007; TORRES SÁnCHEZ, R. (coord.): Volver a la» hora navarra»: la contribución navarra a la construcción de la monarquía española en el siglo XVIII. EUNSA, Pamplona, 2010. 
relacionadas en esencia con la labor de la Tesorería General, una institución analizada con verdadera profusión en los últimos tiempos ${ }^{7}$.

\section{SuJETOS DE DEMANDA Y SISTEMAS DE PROVISIÓN}

No es la primera vez que abordamos estos temas ${ }^{8}$. Sin embargo, al profundizar en nuestro análisis percibimos detalles que pudieron pasar desapercibidos en una primera revisión. Así que, sin ánimo de ser reiterativos, vamos a desarrollar dos reflexiones previas necesarias para una correcta interpretación de nuestra ulterior exposición temporal. Se trata de reflexionar sobre el volumen numérico de los cuerpos que forman el conjunto del ejército y la necesidad de renovar sus uniformes, así como las diversas vías de suministro de los géneros.

2.1. Una cuestión de demanda: La coincidencia entre los datos de nuestros anteriores estudios sobre vestuario con los de Torres Sánchez relativos a la provisión de víveres, nos ha permitido observar una diferenciación permanente en las vías de provisión de los distintos cuerpos del ejército español ${ }^{9}$. Parece que, si hablamos

7. Archivo General de Simancas [en adelante AGS], Dirección General del Tesoro [en adelante DGT], inv. 16, guión 24, leg. 1 y AGS, DGT, inv. 25, guión 1, leg. 17. Los estudios de Anne Dubet sobre la Tesorería General se concentran en el primer cuarto del siglo XviI y han servido para desentrañar los orígenes y el funcionamiento de la institución. Véase, entre sus muchos artículos, DUBET, A.: « $\dot{i}$ Tesorería Mayor o Tesorería General? El control contable en los años 1720: una historia conflictiva», en De Computis, 13 (2010), pp. 95-132 y, uno de los más recientes, Dubet, A.: «José Patiño y el control de la Hacienda. ¿Una cultura administrativa nueva?» en LÓPEZ Díaz, M. (ed.): Élites y poder en las monarquías ibéricas: del siglo XVII al primer liberalismo. Editorial Biblioteca Nueva, Madrid, 2013, pp. 39-56. Torres Sánchez estudia la evolución de esta institución durante la segunda mitad del siglo XVIII; su magnífica monografía TORRES SÁNCHEZ, R.: La llave de todos los tesoros. La Tesorería General de Carlos III. Silex, Madrid, 2012 nos aporta un conocimiento exhaustivo de la institución en sus más diversos ámbitos. Una recopilación de estudios referidos a la Tesorería General en Solbes Ferri, S.: «La Hacienda Real y el control del gasto. La Tesorería General en la España del siglo XVIII» en LuXÁn Meléndez, S. (dir.): Política, empresa e historia en Canarias. Fundación MAPFRE-Guanarteme, Las Palmas de Gran Canaria, 2012, pp. 141-180.

8. Véase SOlBes FerRI, S.: «Contracting and Accounting: Spanish Army Expenditure in Wardrobe and the General Treasury Accounts in the Eighteenth Century» en HARDIng, R. y SOlbes FerRi, S. (eds.): The Contractor State and Its Implications, 1659-1815. Universidad de Las Palmas, Las Palmas de Gran Canaria, 2012, pp. 273-293; SOlbes FerRI, S.: «La demanda de vestuario para el Ejército español en el siglo XVIII», XII Congreso de la FEHM (León, 20-22 Junio 2012) [en prensa].

9. Su primera aproximación a la cuestión del abastecimiento de víveres al Ejército se refiere al ejército regular; véase TORRES SÁNCHEZ, R.: «El gran negocio de la época, la provisión de víveres al ejército por Francisco Mendinueta (1744-1763)» en AQUERRETA, S. (coord.): Francisco de Mendinueta: Finanzas y mecenazgo en la España del siglo XVIII. EUNSA, Pamplona, 2002, pp. 101-134. Años más tarde analizó el abastecimiento diferenciado de la Marina en TORRes SÁNCHEZ, R.: «Los navarros en la provisión de víveres a la Armada española durante el siglo XVIII» en TORRES SÁNCHEZ, R. (ed.): Volver a la "hora navarra». La contribución navarra a la construcción de la Monarquía española en 
de suministros, no nos estamos refiriendo a un ejército unificado, sino al menos a cuatro cuerpos que necesitamos diferenciar. Aprovecharemos esta descripción para valorar además el número de uniformes que necesita cada uno de ellos.

Un primer grupo lo forma la tropa de la Casa Real, un cuerpo privilegiado compuesto por soldados de caballería (guardias de corps y carabineros reales) e infantería (compañía de alabarderos y reales guardias) ${ }^{10}$. Hablamos de cuerpos de élite, un reducto para la aristocracia, formados por cerca de 1.000 unidades de caballería, 100 alabarderos y, el grueso del grupo, entre 8.000 y 6.000 guardas reales (en ocasiones integrados con el ejército regular). Sus uniformes son bastante más costosos que los de la tropa regular, su provisión se considera prioritaria y su localización es siempre cercana a la Corte y los Reales Sitios (salvo las reales guardias).

El segundo grupo de provisión se refiere al ejército regular de tierra compuesto, a su vez, por varios apartados. El principal se refiere a la tropa regular o de veteranos, formada por regimientos de infantería española y extranjera (subdivididos en batallones de 700 hombres y compañías de 100) y por compañías de caballería y dragones (de unos 150 hombres subdivididos en escuadrones). Ozanam calcula como cifra indicativa de su tamaño para los años que nos ocupan la de 90.000 hombres, siempre en el caso de que los regimientos estuvieran completos, cuestión harto complicada ${ }^{11}$. Cabe añadir a ellos el cuerpo de inválidos -soldados no aptos para el servicio en campaña pero útiles en las guarniciones- cuyo número oscila entre 4.000 y 6.000 hombres. También los 23.000 hombres que forman los regimientos de milicias provinciales destinados a guardar las fronteras del territorio de su recluta, especialmente cuando el ejército regular sale en campaña ${ }^{12}$. No parece que la Corona tuviera la obligación de vestir a estos últimos, sí de armarlos, pero su consolidación fue tan rápida que en 1743 se extrajeron siete regimientos de milicianos para Italia uniformados, en este caso sí, por cuenta de la Real Hacienda.

el siglo XVIII. EUNSA, Pamplona, 2010, pp. 213-262. Y recientemente ha centrado su interés en el abastecimiento de cuerpos de la Casa Real; Torres Sánchez, R. «Los Cinco Gremios Mayores y el abastecimiento de víveres al Ejército Español en el siglo XVIII», Studia Historica. Historia Moderna, 34 (2012), pp. 407-432.

10. ANDÚJAR Castillo, F.: «Elites de poder militar: las Guardias Reales en el siglo XVIII», en Castellano, J. L.; Dedieu, J. P.; y López Cordón, M. ${ }^{a}$ V. (eds.): La pluma, la mitra y la espada. Estudios de historia institucional en la Edad Moderna. Madrid, 2000, pp. 65-94; ANDÚJAR CASTILLO, F.: «La Corte y los militares en el siglo XVIII», Estudis, 27 (2001), pp. 91-120.

11. Ozanam, op. cit., cuadro 2, p. 530. El número máximo de efectivos movilizados en la primera mitad del siglo fue durante la guerra de Sucesión, pero volvió a alcanzarse un número similar con el inicio de la campaña de 1734 que se mantendría con escasas oscilaciones hasta 1748.

12. La Real Ordenanza de 31/01/1734 dispuso la organización en las provincias de Castilla de 33 regimientos de milicias formados por un batallón de 700 hombres dispuestos en siete compañías de cien hombres cada una. 
No podemos olvidar, por último, al cuerpo facultativo de artilleros compuesto por unos 2.000 hombres incluidos en un regimiento independiente. En resumen, podemos estar hablando hasta ahora de unos 100.000 hombres en activo.

Todavía existe una tercera y una cuarta vía para la provisión de tropas. Una de ellas se refiere a la marina que se constituye como un cuerpo especialmente complejo para su análisis, pues conserva su propia Secretaría de Estado desde 1714, su Intendencia desde 1717 y su contaduría, separada de la del ejército de tierra, desde estas mismas fechas. En tiempos de Patiño comenzó su financiación diferenciada, complicada incluso con la creación -a imitación británica- del Almirantazgo bajo el cargo del Infante don Felipe, dotado con sus propios recursos y vías de financiación ${ }^{13}$. Patiño creó asimismo un cuerpo de batallones de Marina formado por 2.500 hombres, cuyo número fue aumentando hasta superar los 7.000 en 1741 cuando alcanzó los diez batallones. La última vía de provisión, que prácticamente no aparecerá en nuestro texto, se refiere a las guarniciones de los presidios de África (Ceuta, Orán más los tres presidios de Melilla, Alhucemas y Peñón de Vélez). Su independencia en el suministro proviene del hecho de que su dotación financiera se encuentra directamente consignada sobre los fondos de la bula de la Santa Cruzada y, aunque dichos fondos se incorporan al control de la tesorería general en 1753 , sus suministros mantendrán ciertas prerrogativas a la hora de su contratación.

Por un informe de 1749 sabemos que el uniforme de cualquier militar se considera devengado a los cuarenta meses; en el ínterin, los soldados recibían simplemente el llamado medio vestuario que incluye prendas interiores que necesitan renovarse más a menudo ${ }^{14}$. Como los distintos cuerpos y regimientos se renuevan por turno, y nos consta que los retrasos son habituales, pensamos que resulta realista considerar el coste de renovación completa del vestuario de todo el ejército como la suma de lo abonado durante cuatro anualidades. Así que podemos resumir esta apartado con la idea de que la Corona va a tener que fabricar o financiar durante los ocho años que nos ocupan algo más de 200.000 uniformes, por lo menos 25.000 al año. La Real Hacienda necesitará gestionar dicha provisión teniendo en cuenta además la necesidad de formar contratos independientes para

13. Sobre la Marina española del siglo XviII véase Cervera Pery, J.: La Marina de la Ilustración (resurgimiento y crisis del poder naval). San Martín, Madrid, 1986; CASADO RABANAL, D.: La marina ilustrada. Sueño y ambición de la España del siglo XVIII. Desarrollo y crisis (1702-1805). Ministerio de Defensa, Madrid, 2009; y SAAVEDRA VÁzQUEZ, M. C.: «Política naval y guerra marítima en la España del Antiguo Régimen», en García Hurtado, GonzÁlez Lopo y Martínez Rodríguez (eds.): El mar en los siglos modernos. Xunta de Galicia, Santiago de Compostela, 2008, t. II, pp. 17-51. Desde un punto de vista institucional Perona TomÁs, D. A.: La Secretaría de Estado y del Despacho de Marina. La institución y los hombres (1714-1808). Universidad de Murcia, Murcia, 1995.

14. AGS, DGT, inv. 25, guión 1, leg. 17. 
cuerpos de élite, ejército regular (el expedicionario y el que se mantiene en la Península), batallones de Marina y, en su caso, tropas de los presidios africanos.

2.2. Una cuestión de oferta: No parece imposible, aunque tampoco sencillo, atender correctamente las necesidades de suministro comentadas. La cuestión primordial es el cómo, así que necesitamos abundar en el dilema del Estado borbónico entre producir los géneros, comprarlos o una tercera alternativa, hasta ahora poco comentada, como es la de financiar sencillamente las compras ${ }^{15}$. Jamás se renunció al propósito de cubrir la demanda mediante producción nacional $y$, quitando el tiempo del conflicto sucesorio, esta fue normalmente capaz de responder a la intención manifestada ${ }^{16}$. Otra cuestión es la posibilidad de fabricar los paños en fábricas reales y construir uniformes bajo el control directo de la Corona. Desde el tiempo de Patiño, se observa una escalada intervencionista por parte de la Corona estimulando el desarrollo de las reales fábricas que, en todos los casos, se justifica por el deseo de suprimir intermediarios por razones de estrategia, calidad o control de la producción. En todo caso, la opción resulta tan deseada como habitualmente irrealizable, por una cuestión tan sencilla como el ahorro de costes que suele llevar aparejado el recurso al intermediario, nacional eso sí. De modo que una y otra vez llegamos a la inevitable necesidad de recurrir al mercado, a mediadores capaces de movilizar las fuerzas productivas necesarias para garantizar la provisión. Con todo, no debemos olvidar la posibilidad de una tercera vía consistente en desentenderse del control de la producción para entregar sencillamente a los regimientos el dinero necesario para vestirse por su cuenta. En la práctica, las tres fórmulas fueron constantemente ensayadas e incluso alternadas.

-Solución 1a: Comprar. Hay que diferenciar dentro de este apartado el recurso a asientos generales de la firma de contratas puntuales. Son términos equivalentes en la documentación y similares en sus trámites legales o procedimientos contractuales, pero la gran diferencia es que el asiento se constituye como un contrato indefinido entre demandante y productor para la provisión continuada de géneros según una serie de condiciones relativas a calidades, precios o período de vigencia. La contrata es, sin embargo, puntual y limitada en cuanto a cantidad, condiciones, plazos de entrega y precios, así que finaliza en el momento de su cumplimiento. La provisión de uniformes a la infantería suele hacerse por asiento pero la de

15. Véase notas 2 y 3.

16. Las compras en el extranjero sí fueron necesarias en otros ámbitos relacionados con la dotación de los ejércitos como puede ser el armamento y la artillería. Véase GonZÁlez ENCISO, A.: «Buying cannons outside: when, why, how many? The supplying of foreign iron cannons for the Spanish Navy in eighteenth century» en Harding, R. y Solbes Ferri, S. (eds.): The Contractor State and Its Implications, 1659-1815. Universidad de Las Palmas, Las Palmas de Gran Canaria, 2012, pp. 135-158. 
tiendas de campaña, juegos de montar o sombreros, por citar algún caso, suele gestionarse a través de una contrata.

El procedimiento de formación de un asiento general entre la Corona y un agente privado arranca con la comunicación de la demanda de la Corona a través de real orden y continúa con la presentación del pliego con las condiciones del candidato a satisfacerla. La Corona puede intentar, mediante negociación directa o recurso al sistema de mejoras, fomentar la competencia entre demandantes a través del Consejo de Hacienda, la institución tradicionalmente encargada del negociado de asientos que, aunque conserva las funciones administrativas, había perdido mucha autoridad en la práctica. La constante rivalidad entre la institución mencionada y las Secretarías del Despacho de Guerra-Marina y Hacienda viene determinada por el deseo de intervenir en la provisión que siente tanto el que paga, como el que gestiona contratos, como el que utiliza los géneros adquiridos. En nuestra coyuntura histórica, lleva ventaja la secretaría de Hacienda porque desde arriba se desea poner coto tanto al poder y autonomía financiera de los militares como al antiguo sistema polisinodial ${ }^{17}$.

Comunicadas y resueltas las eventuales discrepancias, el asentista presenta un pliego de allanamiento para ser aprobado por real orden y registrado ante escribano público. Adquiere entonces valor de contrato de obligado cumplimiento, con garantía de fianzas y bienes del asentista, mientras la Real Hacienda se compromete a abonar el valor de las entregas en los plazos establecidos. El contrato define hasta el último detalle la forma, calidad y composición de los uniformes, así como las condiciones de pago y los privilegios para el intermediario y los productores. Con todo, el asentista no sabe todavía a qué regimiento, compañía o escuadrón debe surtir en cada momento concreto; esta información la va recibiendo puntualmente a través de nuevas órdenes.

En el momento de la entrega efectiva de los géneros, el asentista recoge el recibo de certificación firmado por un agente habilitado por cada cuerpo -normalmente un teniente escogido por el coronel y el resto de oficiales-. Con este recibo puede presentarse ante la tesorería general que es la institución encargada de gestionar los abonos de la Real Hacienda, siguiendo instrucciones del secretario de Hacienda. El dinero, de todos modos, puede circular previamente bajo la forma de adelantos, créditos, letras o abonos en diferentes tesorerías reales, de modo que resulta necesario ajustar cuentas cada cierto tiempo a través de lo que se conoce precisamente como ajustamiento entre asentista y tesorería. Este documento refleja el acuerdo de las cantidades a liquidar suscrito entre ambas partes. Con el visto bueno de los contadores de la tesorería, el tesorero general autoriza el libramiento de cartas

17. El proceso de imposición de la Secretaría de Hacienda en el control de caudales sobre el resto de instituciones señaladas en TORRES SÁNCHEZ, La llave de todos los tesoros..., pp. 21-42. 
de pago por el valor acordado y el asentista otorga recibo de abono por la misma cantidad, que el tesorero general incluye en la cuenta de su ordenación ${ }^{18}$.

El método descrito se aplica de manera muy similar a la formación de contratas puntuales para provisiones menores aunque se observa una cierta simplificación en el proceso de su ejecución. Se parte igualmente de una real orden que señala una propuesta de provisión concreta -sin pliego de condiciones-, se sigue con el allanamiento, la aceptación de la Corona y la formación de escritura ante escribano, con proceso de otorgamiento de fianzas incluido. Resulta habitual en las contratas, menos en los asientos, que la tesorería general adelante una buena parte del coste de producción por vía de anticipación al fabricante. El modelo de certificación de entrega y recepción de géneros por parte de las autoridades militares es el mismo, así como la forma en que, con el recibo firmado por el habilitado, el proveedor acude a la tesorería general para obtener las cartas de pago que le permiten cobrar sus emolumentos sin necesidad de ajustamiento, pues los abonos han quedado previamente definidos en las condiciones de la contratación.

-Solución 2a : Producir. El aprovisionamiento del Ejército genera una esquizofrenia permanente en los ministros de la Corona, pues el recurso a asientos de provisión que acabamos de describir realmente funciona y se convierte en fórmula dominante durante todo el siglo. El problema es que nunca parece la solución deseada, por la permanente sospecha de que el asentista se lucra exagerada e indebidamente a costa del Estado. Los administradores de la Real Hacienda nunca se resignaron y siempre recurrieron al argumento de la necesidad del control directo de la Corona. Esta circunstancia es especialmente trascendente en las décadas de 1730 y 1740, de oposición continua al papel jugado hasta entonces tanto por asentistas como por arrendadores de rentas. En el caso del vestuario, parece existir además un convencimiento pleno a la hora de interpretar que la materia prima, la producción nacional de paños en las fábricas reales y el control del Estado podría ser algún día bastante para vestir a todo el Ejército.

El principal desarrollo de esta política se tradujo fundamentalmente en el fomento de los almacenes ubicados en la Corte de Madrid, receptores de paños de lana elaborados en villas cercanas, que servían a los gremios de Madrid para que confeccionaran los uniformes. En 1747 Ensenada hablaba de los motivos que llevaban al fomento de este sistema, "proveer el vestuario de las tropas

18. Otra cuestión es si el asentista cobra puntualmente o no las cartas de pago que presenta en tesorería. En caso de dificultades presupuestarias, estas cartas de pago podían llegar a consolidarse como una especie de deuda pública convirtiéndolas en los llamados boletines que se trasfieren de un tesorero a otro. Es una cuestión muy compleja sobre la que actualmente trabaja Anne Dubet. Estamos a la espera de sus resultados en el corto plazo. 
con beneficio común de las fábricas del Reyno y en especial de las de Castilla» ${ }^{19}$. Sabemos que la creación de los almacenes la dispuso Alberoni en 1715, pero su actividad se fue disolviendo lentamente. En la década de 1730, Patiño trató de introducir un nuevo modelo de gestión directa por parte de la corona apoyada en la propia administración militar y los intendentes de ejército, que actuaban en las provincias como directores de provisión, mientras que el control contable quedaba en manos de una Contaduría General de Provisiones expresamente creada para tal fin ${ }^{20}$. Son los sucesores de Patiño los que deciden retomar la opción de los almacenes para producir al menos los uniformes de la tropa ubicada cerca de Madrid. Según RD 25/09/1739, comunicada por el secretario de Hacienda Iturralde al tesorero Prado Güemes:

que el vestuario de las tropas se hiciese en la forma que se había practicado en tiempo antecedente -ajustando contratas con diferentes pueblos y personas dependientes de los gremios de Madrid para la provisión de paños y demás géneros precisos para el mismo vestuario-, mandó que (...) se depositasen los géneros y el vestuario en una bóveda que a este fin se había destinado de su real orden en el cuartel de Guardias de Corps ${ }^{21}$.

Además del privilegio que representa la elección directa como proveedor de la Corona, se ofrece la entrega de cierta cantidad de dinero como anticipación, la libertad de derechos de tránsito así como la posibilidad de liberar a todos los habitantes de la villa de quintas y sorteos por considerarlos dependientes de la fábrica. Las condiciones posteriormente ajustadas por el encargado del almacén con los gremios de Madrid se parecen bastante al modelo de contrata expuesto en el epígrafe anterior. Los regimientos uniformados a través de esta vía, que podríamos definir como emancipada de asentistas, serían directamente designados por la Corona. Una fórmula, en definitiva, siempre deseada, siempre fomentada y siempre ineficiente.

-Solución 3a: Pagar. También hemos comentado la posibilidad de que los regimientos recibieran el valor en metálico del coste de su aprovisionamiento para que fueran sus propios oficiales los encargados de la contratación. En estos casos, se emite la preceptiva real orden, comunicada por el secretario de Hacienda al tesorero general, para que se entregue el dinero al oficial habilitado por el regimiento; el habilitado no gestiona en este caso certificados de entrega, sino cartas de pago en firme por el valor del dinero recibido, que el tesorero incluirá en la

19. Real Resolución de 01/05/1747, comunicada por Ensenada a su tesorero Horcasitas; AGS, DGT, inv. 25, guión 1, leg. 17.

20. Un sistema parecido al del Victualling Board inglés. Véase Torres SÁnchez, op. cit., 2002, p. 492.

21. AGS, DGT, inv. 16, guión 24, leg. 1, carp. 2. 
cuenta de su ordenación. Aunque la documentación no explica cómo y con quién entra en contacto el coronel del regimiento, los asentistas protestaron vivamente contra esta fórmula de provisión, por considerarla incompatible con las condiciones establecidas en sus contratos. Tampoco podemos conocer la mayor o menor eficacia del método. Puede que fuera la vía más cómoda para la administración y aún la más dinamizadora de los mercados, a través de una demanda pública que se diversifica entre proveedores cercanos a la ubicación del regimiento. Pero esta solución es, a la vez, opuesta al programa político regulador que Felipe V trataba de imponer desde los inicios de su reinado y no cumple sobre todo con la función de retirar el control de las finanzas públicas de manos de los militares. Cuando la tesorería general abona el dinero, la secretaría de Hacienda pierde el control sobre la contratación que pasa a los militares e, indirectamente, a la secretaría de Guerra. En consecuencia, la secretaría de Hacienda se opondrá sistemática a un sistema que se encuentra en trance de desaparecer durante las décadas de 1720 y 1730.

\section{La contratación del vestuario en tiempos de Campillo y Ensenada} (1741-1748)

Abandonamos el plano teórico para centrarnos en el terreno de las realidades, de los contratos firmados durante la época de la tercera campaña de Italia. Nuestra principal intención es responder a la pregunta de si Campillo y Ensenada, en sus primeros años de gobierno, seguían contando con los asentistas en este asunto y hasta qué punto fueron capaces de encontrar alternativas de provisión. La cuestión es pertinente por dos motivos: el primero porque tradicionalmente se achaca la suspensión de pagos de 1739 a los abusos y manejos de asentistas y arrendadores de rentas; y el segundo porque, a partir de esta coyuntura, parece avanzarse efectivamente en un proceso de imposición de la administración directa de rentas (alcanzado definitivamente en torno a 1749) que suprimiría la actividad de los arrendadores. ¿Qué ocurre mientras tanto con los asentistas? En el conocido artículo de Pablo Fernández Albadalejo sobre la suspensión de pagos se nos indica que Patiño trampeó continuadamente con asentistas y arrendadores de los que consiguió sacudirse el yugo; sus sucesores abrieron sin embargo un período de regresión en la línea emprendida, lo que provocó que el sistema tocara techo con la propia suspensión. Campillo representa entonces la adopción del principio de administración directa y de una nueva actitud de dureza con arrendadores y asentistas «que puede considerarse también como un primer paso hacia su liquidación» ${ }^{22}$. La historiografía tradicional ha asumido por

22. Fernández Albadalejo, P.: «El decreto de suspensión de pagos de 1739: análisis e implicaciones», Moneda y crédito, 142 (1977), pp. 64-69. 
defecto la idea de que a los asentistas les tuvo que pasar más o menos lo mismo que a los arrendadores, aunque en los últimos tiempos han aparecido estudios que ponen en cuestión dicha afirmación ${ }^{23}$.

Para desarrollar este análisis necesitamos ajustarnos, no exactamente al tiempo de actuación de los grandes ministros, sino al de sus tesoreros generales. En este sentido, hay que explicar que, aunque el propósito enunciado era que las cuentas de los tesoreros fueran anuales y alternantes -cada año debía concluir su labor un tesorero, que pasaría a labores de ordenación, siendo reemplazado por otro tesorero y así sucesivamente-, este propósito resultaba por el momento irrealizable ${ }^{24}$. El motivo principal está relacionado con la dificultad en la presentación y confirmación de cartas de pago y deudas transferidas de un tesorero a otro a través de los famosos boletines de los que hemos hablado anteriormente. El caso es que el tiempo de actuación de los tesoreros resulta finalmente indeterminado y que la orden de pasar a ordenación suele coincidir con un cambio político. Se trata de una situación que no se resolverá hasta 1753, fuera ya del marco temporal de este estudio.

Así, en febrero de 1741, Campillo ocupaba el cargo de secretario de Hacienda $y$, en octubre, incorporaba a sus funciones las de secretario de Guerra y de Marina e Indias. El tesorero general era entonces Manuel del Prado Güemes, por cuenta de la casa del conde de Moriana, y había sido nombrado por Iturralde poco después de la suspensión de abril de 1739. Prado Güemes fue inmediatamente relevado del cargo en marzo de 1741 y remplazado por José Gómez de Terán, marqués del Portago, quien se mantendría en el cargo hasta los inicios de 1747. Campillo falleció en abril de 1743, pero Ensenada le mantuvo como muestra de la continuidad de sus políticas. Sin embargo, al finalizar ese mismo año 1743, exigió al tesorero la formación de la cuenta por los ya casi tres años de ejercicio transcurridos. Es este el documento que nos sirve como referencia para el tiempo de Campillo.

Gómez de Terán fue sustituido por Manuel Antonio de Horcasitas el 31 de enero de 1747, pasando a labores de ordenación y preparación de su segunda cuenta. Suponemos que la guerra mostraba visos de agotamiento y era un buen momento para el cambio de un tesorero con más de seis años en activo. Horcasitas se mantendría en el ejercicio continuado de su cargo hasta el final de 1750 pero, justo al terminar 1748, recibiría la orden de ajustar la que sería su primera cuenta. El tiempo de Ensenada que abarcamos tendrá, por tanto, su desarrollo en la segunda cuenta de Gómez de Terán (1744-enero de 1747) y la primera de Horcasitas (resto de 1747 y 1748).

23. Torres SÁnchez, op. cit., 1999 y 2002; Torres SÁnchez, La llave de todos los tesoros..., pp. 28-30.

24. No se logró alcanzar hasta 1753. Véase Torres SÁnchez, La llave de todos los tesoros..., pp. 34-35. 


\subsection{La reorganización de Campillo de la provisión de vestuario}

Un informe previo referido al año 1737 nos proporciona el listado de asentistas de vestuario vigente para ese año (cuadro $n^{\circ} 1$ ). No debemos detenernos en su análisis, pero conviene señalar que las cantidades ofrecidas son excesivas para una única anualidad, así que pensamos que pueden incluir deudas pendientes. Simplemente pretendemos utilizar esta referencia para conocer quiénes fueron los asentistas de vestuario ascendidos tras la muerte de Patiño. Resulta evidente en este sentido que, la mayor parte de la provisión -exceptuando la referida a tropas de élite-, se encuentra absolutamente monopolizada por Matías de Valparda.

Cuadro 1. Obligaciones anuales para 1737 de la mesa de asientos y provisiones de la Tesorería General relacionadas con vestuario (en reales de vellón)

\begin{tabular}{|l|r|}
\hline Antonio de Lambarri: camas y utensilios tropas reales & 389.849 \\
\hline Matías de Valparda: vestuario de la tropa regular & 7.000 .000 \\
\hline Matías de Valparda: vestuario de guardias reales de infantería & 5.000 .000 \\
\hline José Cebrián: vestuario de gaurdias de corps & 1.785 .678 \\
\hline Simón del Valle: vestuario de alabarderos & 177.136 \\
\hline Pedro Santos: conducción de vestuarios & 70.831 \\
\hline
\end{tabular}

Fuente: Elaboración propia sobre AGS, Secretaría y Superintendencia de Hacienda [en adelante SSH], leg. 408-1.

Nos trasladarnos directamente al año 1741 para que Campillo comience a personalizar el retorno a una aparente normalidad en la gestión de la Real Hacienda, después de las convulsiones de la suspensión, el inicio de la guerra contra Inglaterra y la pronta decisión de emprender una nueva campaña en Italia. En el cuadro $n^{\circ} 2$ reflejamos las contrataciones efectuadas bajo su supervisión para la dotación del vestuario tanto de los ejércitos expedicionarios como de la tropa que permanece en territorio peninsular. 
Cuadro 2. Cuenta del tesorero general José Gómez de Terán, marqués de Portago, de lo abonado por vestuario del Ejército (01/03/1741 - 31/12/1743) (en reales de vellón)

\begin{tabular}{|l|r|r|}
\hline A) A disposición de la Secretaría de Guerra del duque Montemar & 1.975 .094 & $13,9 \%$ \\
\hline B) Asentistas generales y contratas & 11.531 .645 & $81,4 \%$ \\
\hline Matías de Valparda (ejército expedicionario) & 6.155 .917 & \\
\hline Mateo López de Sedano & 2.574 .496 & \\
\hline José de Florenza y Pons (ejército expedicionario) & 922.056 & \\
\hline José Cebrián (guardas de corps) & 790.866 & \\
\hline Herederos Antonio Lambarri (camas y utensilios) & 554.313 & \\
\hline Juan Vedime (atrasos) & 263.472 & \\
\hline Jaime Planell (alabarderos) & 200.195 & \\
\hline Pequeñas contratas con proveedores & 70.330 & \\
\hline C) Almacenes de laCorte & 541.066 & $3,8 \%$ \\
\hline Provisiones de los almacenes generales (batallones de Marina) & 261.779 & \\
\hline Villas productoras de paños & 176.990 & \\
\hline Conductores de vestuario & 67.014 & \\
\hline Salario dependientes del almacén & 35.284 & \\
\hline D) De cuenta de los propos cuerpos & 114.622 & $0,8 \%$ \\
\hline TOTAL & 14.162 .428 & $100 \%$ \\
\hline
\end{tabular}

Fuente: Elaboración propia sobre AGS, DGT, inv. 16, guión 24, leg. 1, carp. 2.

La imagen que nos transmite el cuadro es la de un predominio absoluto de la contratación a través de asentistas generales, con Valparda al frente de ellos, Cebrián en guardias de corps y Lambari en camas y utensilios. Se observa en definitiva la prolongación de los datos de 1737. Lo único excepcional es la partida de dinero sujeta a la gestión de la Secretaría de Guerra, con ella iniciaremos nuestro análisis.

3.1.1. A través de una Ro de 10/03/1741, comunicada por Campillo a Gómez Terán, se le ordenó al tesorero abonar al ministro de la guerra DUQUE DE MONTEMAR la segunda mitad del dinero correspondiente al encargo de proveer el vestuario del «Ejército de Prevención (...) como se había practicado con el marqués de Iturbieta». El ejército de prevención se refiere a las tropas destacadas en las guarniciones de Italia que, al parecer, estaban siendo provistas por Miguel de Arizcun, marqués de Iturbieta. Arizcun no es un secretario de Estado sino un asentista, navarro para más señas, conectado con los círculos de Goyeneche y del secretario 
de Hacienda Iturbide ${ }^{25}$. En el año 1740, le fueron abonados hasta 3,5 millones de reales para mantenimiento y renovación de uniformes pero, ¿qué relación existe entre Arizcun y la secretaría de Guerra y por qué gestiona tanto dinero? Esperamos poder ofrecer pronto un análisis en profundidad de esta etapa pero, por el momento, no podemos decir más. Desde este momento, el dinero no se transfiere a un asentista sino al propio secretario de la Guerra, quien dispondría de la posibilidad de otorgar libranzas asignadas a un fondo de hasta 3,5 millones de reales.

Montemar gastó de este fondo 230.000 reales en vestir a los regimientos de infantería de la Reina y de Castilla, a la compañía de granaderos del regimiento de África, compró banderas y cajas al de Portugal y sables granaderos al de Aragón; todo ello ofreciendo el dinero para que construyeran de su cuenta. Abonó asimismo una letra por valor de 400.000 reales al marqués de Iturbieta por gastos de ejecución del vestuario en Barcelona ${ }^{26}$. También abonó al asentista Mateo López de Sedano, del que más tarde hablaremos, 608.357 reales por 2.339 vestidos construidos en la Corte para nuevas reclutas de infantería (260 reales/ uniforme). Al apoderado del asentista catalán Juan de Benime se le pagaron 700.000 reales por el vestuario realizado en Cataluña para cinco regimientos de infantería, uno de caballería y cinco de dragones. Y, finalmente, abonó 42.551 reales a José Gallo, encargado de los almacenes reales de la Corte, por gastos de conducción de vestuarios hasta Barcelona y otros parajes. En resumen, Montemar gastó el dinero utilizando todas las fórmulas de provisión que destacamos en el epígrafe anterior. La única característica común a todos estos abonos es que la fecha de su ejecución corresponde a la primera mitad del año 1741, mientras Campillo se acomodaba en el ejercicio de su poder. Quiere esto decir que Campillo estaba cumpliendo simplemente con la ejecución de los contratos pendientes; no tardaría un segundo más de lo necesario en poner fin a un sistema que no era de su agrado, para devolver el control absoluto de la contratación a la secretaría de Hacienda a través de la tesorería general.

3.1.2. En este momento, se adoptan una serie de decisiones trascendentales, como la de ponerse en manos de asentistas generales para garantizar la provisión del vestuario durante la siguiente campaña. Sigue a continuación el detalle de los contratos de Campillo con asentistas para la provisión de los distintos cuerpos.

Matías de VAlParda, de Barcelona, fue el asentista escogido para la construcción del vestuario de los regimientos de infantería del ejército expedicionario que alcanzaría los 60.000 efectivos en el momento de su traslado. Por la Ro de

25. AquerretA, op. cit., 2000, pp. 659-678.

26. Juan de Urrutia (de Barcelona) giró la letra sobre dicho marqués y a favor de Benaje, Andreu y Milans en AGS, DGT, inv. 16, guión 24, leg. 1, carp. 2. 
07/03/1742 admite SM el pliego de Valparda para la provisión de doce regimientos de 1.360 hombres cada uno (214,5 reales/uniforme), en la misma forma que lo ejecutó en los años 1735, 1736, 1737 y $1738^{27}$. Ya sabemos que Valparda no es nuevo en la plaza y, lo que parece ocurrir, es que recupera en realidad el puesto que le arrebató Miguel de Arizcun entre 1739 y 1741. Gómez de Terán gestionó cuatro ajustamientos con Valparda entre mayo y octubre de 1742 para el abono al asentista de más de 3,5 millones de reales (confirmados por RD de 09/12/1744).

Tras la salida de la tropa a tierras italianas, Valparda continuó trabajando para renovar suministros. La RO de 03/04/1743 le instaba a vestir a un batallón de la nueva leva de Saboya con 667 uniformes por 150.000 reales (224,9 reales/uniforme) con una curiosa forma de pago. Se apunta cuidadosamente en el contrato la cláusula de que el dinero se «debía descontar a favor de la Real Hacienda sobre la paga de los oficiales del batallón a la mitad de su haber hasta el reintegro» ${ }^{28}$. Seguramente el coste de mantenimiento de los regimientos estaba calculado sobre la base de las transferencias de dinero hechas a los oficiales; los uniformes se remitirían desde Barcelona, por cuenta de la Corona, pero su valor debía posteriormente descontarse de lo abonado a estos oficiales en campaña. El resto de provisiones de Valparda se entregaron en España y corresponden al año 1743. Se conservan hasta doce recibos firmados por oficiales habilitados y un ajustamiento de julio de 1743 por razón de otros 2,25 millones de reales. De modo que podemos afirmar sin temor a equivocarnos que Valparda fue el principal asentista de vestuario del tiempo de Campillo y de la campaña italiana.

Un segundo asentista para provisiones asimismo del cuerpo expedicionario fue don José de Florenza y PONs. La RO de 20/04/1742 le autorizaba a percibir el valor del vestuario suministrado en Cataluña a los regimientos de infantería de Córdoba, Milán y Mérida, junto con el de dragones de Francia. La referencia para la composición de los mismos fue el asiento de Valparda, aunque teniendo en cuenta que debía bajarse de su coste «lo que hubiese percibido en Barcelona [de los almacenes reales] a buena cuenta de este haber». Por este detalle sabemos que Florenza concentra su labor en Barcelona. La Ro de 16/08/1742 resolvía que se formasen en Cataluña dos compañías de fusileros de Montaña de 100 hombres cada una, vestidos y armados por cuenta de la Real Hacienda; para ello, el intendente de Cataluña debía atender las necesidades del asentista en función del allanamiento aprobado por Ro 04/09/1742. Al mes siguiente, la RO de 19/09/1742 ordenaba formar otras ocho compañías de fusileros catalanes, con las mismas condiciones y vestidas por el mismo asentista, con un número de

27. AGS, DGT, inv. 16, guión 24, leg. 1, carp. 2.

28. Contamos con la correspondiente certificación del habilitado, libramiento y recibo más decreto aprobando el abono de 150.938,5 en AGS, DGT, inv. 16, guión 24, leg. 1, carp. 2. 
uniformes que se eleva hasta las 1.000 unidades. En las cuentas y ajustamientos formados aparece el testimonio de la provisión de materiales desde el almacén de vestuarios dependiente de la autoridad ejecutiva del intendente don Antonio Sartine. Florenza, a diferencia de Valparda, percibe además sus abonos en la ciudad condal a través de la tesorería de Ejército de Cataluña, por orden del intendente, por mano del tesorero y bajo el control del contador de dicha tesorería. Así, de 922.000 reales que se le debían, se le abonaron «892.056 de ellos por mano de don Juan Martín de Santesteban, tesorero que fue del Ejército y Principado de Cataluña, y [solo] los 30.000 reales restantes por la Caja principal de la Tesorería General» ${ }^{29}$.

Las fechas nos indican asimismo que el trabajo de Florenza se concentra en el año 1742. En consecuencia, parece que Valparda es el asentista de referencia que, aunque trabaja en Cataluña, lo hace de forma autónoma y manteniendo una relación directa con la tesorería general. Florenza, también catalán, concentra toda su actividad entre los almacenes, la tesorería y en su relación con el intendente de Cataluña que parece ser la persona encargada tanto de su elección como del control de su actividad. Tal como había dispuesto Patiño en su momento.

El caso de JuAn DE BEDIME se refiere básicamente a la percepción de un atraso, pero sus relaciones incluyen noticias interesantes como que sus antiguos contratos sirvieron como referencia para establecer los vigentes. Se trata de un antiguo asentista que guarda relación con José Florenza; es posible incluso que Florenza sea su sucesor en la dirección de la misma compañía. Efectivamente, la RO de 15/12/1741 comunicada por Campillo al tesorero general, ordena abonar a José de Florenza, apoderado de don Juan de Benime, antiguo asentista de vestuarios, el caudal correspondiente al apronto y conducción de 467 vestidos para el regimiento de dragones de Almansa y 1.000 juegos de cartucheras y frascos para la infantería de América, fabricados en Barcelona y entregados en San Sebastián. La fórmula de pago se ajusta al mecanismo utilizado por Florenza pues se le abonaron, «150.000 reales de ellos por mano de don Manuel Vallejo y Sampedro, tesorero que fue del Ejército y Principado de Cataluña (...) y los 113.427 reales y 2 mrs. restantes por la Caja Principal de la Tesorería General» ${ }^{30}$.

Existe un cuarto hombre como es Mateo López de Sedano, de Madrid, cuyo sistema de provisión es diferente al de los catalanes. Dicho asentista recibió encargos continuados, aunque menores, entre septiembre de 1741 y septiembre de 1742, por valor de medio millón de reales. Su gran momento iba a llegar, no obstante, con el inicio de la campaña pues, la Ro de 06/12/1741 aprobaba su pliego para la preparación y entrega en la Corte del vestuario completo de once

29. Ibídem.

30. Idem. 
batallones de infantería. Este encargo le supuso unos ingresos cercanos a los 2 millones de reales. A partir de este punto, se convierte en el asentista encargado de vestir cuerpos «especiales» desde la Corte. Según contrata aprobada de Ro de 16/07/1742 vestiría, por ejemplo, a las 100 plazas de la compañía de Artillería de Orán «a los mismos [precios] que tuvieron de costa a la Real Hacienda para los batallones de Marina» ${ }^{31}$. López de Sedano se convierte así en el eje sobre el que rota la actuación de los almacenes de Madrid para la provisión de la marina y guarniciones de África. Es bastante probable que la intención de la secretaría fuera precisamente la de crear algún tipo de competencia o alternativa a la provisión catalana.

Las tropas de la Casa Real forman, como sabemos, un grupo independiente en su suministro. Las tres compañías de guardias de corps y la guardia de alabarderos lucen uniformes especiales, de mucho más valor que el de la tropa regular. José Cébrí́n es el antiguo asentista de estos cuerpos que, por RD de 14/02/1741, renovó su contrato para vestir a las 300 nuevas unidades de aumento de compañías de corps, con precios y calidades de 1739. El valor de cada uniforme era de 2.092,5 reales, diez veces más que el de un soldado raso; recibiría paños de la fábrica de Guadalajara para casacas, chupas y calzones mientras que «debía ser de su cuenta [adquirir] el paño de las capas, mantillas y tapafundas (de Alcoy veintidoseno azul) y todos los demás géneros como eran galones, hilo, botones, bocací, botas y otros que eran necesarios para cada vestido» ${ }^{32}$. Disfrutaría de franquicia de derechos de entrada en la Corte, pues algunos géneros vendrían de Francia -medias y espuelas-y otros de Bilbao -baquetas y cueros-. La entrega de los uniformes se efectuó entre mayo y julio de 1741 y fue por valor de 627.750 reales a percibir en cuatro mesadas sobre el producto de Rentas Provinciales. La cuenta del tesorero incluye aviso de la anterior tesorería de no haberse satisfecho cantidad alguna a este asentista, así como el descuento por el valor de los paños de Guadalajara (162.900 reales, según aviso del administrador de la fábrica de julio de 1741) y certificación de Salvador de Querejazu, contador de rentas generales, sobre los derechos aduaneros que debían serle reintegrados en virtud de sus franquicias (2.500 reales).

La compañía de alabarderos se viste de cuenta de un asentista distinto, como es Jaime Planell y compañía, quien propuso una mejora del diez por ciento sobre el asiento de Cebrián admitida por RO de 20/09/1740. Debía entregar los géneros en cuatro meses; recibiría la mitad del importe de contado y el resto a la entrega, con certificación del capitán de la compañía. Planell entregó 130 vestidos completos por valor de 144.577 que, con la baja del 10 por ciento, quedaron en 130.119 reales, de los que hay que descontar los 70.046 reales correspondientes

31. Idem.

32. Idem. 
al valor de los paños de Guadalajara. En consecuencia, el uniforme de alabardero ofrece un coste de 1.540 reales, bastante similar al de guardia de corps si consideramos que es tropa de a pie.

Todavía queda un último asiento referido a tropas reales, que afecta en este caso a las guardias reales española y valona, aunque no afecta estrictamente a vestuario sino a camas y utensilios. Dicho asiento, que puede que sea el más antiguo de cuantos hemos mencionado, se encuentra en manos de los HEREDEROS De don Antonio Lambari y Ondazarros. En tiempos de Patiño y por ro de 21/08/1733, comunicada al tesorero Valbuena, aprobó SM el pliego de Lambari para proveer el cuartel de las guardias de corps de Madrid y los reales sitios de San Lorenzo, Aranjuez, El Pardo y San Ildefonso de camas, luz, lumbre y utensilios por tiempo de ocho años. A partir de septiembre de 1733, incluiría la contrata las mesas, bancos, manteles, toallas, carbón, velas de sebo y aceite de faroles. Se detallan las condiciones del transporte de las camas de un lugar a otro (siguiendo los movimientos del rey) y los 500 reales anuales por el gasto de encender los faroles. El caso es que, Antonio Lambari falleció en 1739 y que sus herederos revocaron inmediatamente el poder otorgado a un viejo conocido como es Mateo López de Sedano; el cambio fue admitido por Ro de 21/10/1739. Por otra RO de 08/04/1742 se mandó a los herederos continuar con la provisión por otros ocho años bajo los mismos precios y condiciones. Según aviso de la tesorería de ordenación, habrían cobrado hasta agosto de 1740 y por transportes hasta junio de 1740; lo entregado y ajustado desde esta fecha hasta finales de 1742 equivale a los 278.748 reales que Gómez de Terán le abonó junto con una deuda anterior de 275.565 reales.

3.1.3. Tenemos que hablar ahora del resto de fórmulas de provisión. Efectivamente, las CONTRATAS firmadas con proveedores particulares reflejan unos valores tan insignificantes que basta con señalar que se refieren a la adquisición de complementos, como tiendas o sillas para los caballos, por valor de 70.000 reales. En cuanto a la provisión DE CUENTA DE LOS PROPIOS CUERPOS, señalar que Campillo recurrió a ella solamente en casos puntuales. El del regimiento de inválidos de Galicia porque sus uniformes, fabricados en 1739 por Mateo López de Sedano, se entregaron por orden del capitán general de Galicia a soldados embarcados para América en el puerto de Ferrol; su valor se estimó en 67.500 reales, más los costes del transporte, los mismos que percibió el oficial habilitado en junio de 1742. El segundo caso afecta a las dos compañías de artillería de cien plazas repartidas entre Extremadura, Castilla y Orán; el vestuario se declaró devengado en julio de 1738 pero la Ro de 27/10/1741 todavía habla «de la desnudez que experimentaban ambas compañías, [y] resolvía se les librase con toda brevedad el nuevo vestuario (...) a fin de que con esta providencia quedasen vestidas antes que entrara el rigor del invierno». No pudo sin embargo acudir la tesorería a cubrir dicha providencia 
por no haber géneros disponibles en el almacén, de modo que se sugirió en el mes de enero siguiente la solución de librar su valor equivalente en metálico (16.127 reales para construir 200 uniformes). La tercera partida se refiere al importe de recibos que pasaron al tesorero diversos batallones de infantería por compra de complementos, valorados en 29.145 reales, que presentan la característica común de haber sido todos ellos abonados en tesorerías de las Provincias donde cada uno se ballaba $a^{33}$.

Así que la única alternativa real al negociado con asentistas privados parece ser la ejecución del vestuario a través de los ALMACENES REALES, con paños de las villas cercanas, elaborados por los gremios madrileños. Sus costes se organizan en un doble nivel. El veedor del almacén, don José Gallo, asistido por Juan de Beñatena en la medición y reconocimiento de paños y por Pedro Santos Gómez en el ajuste de los portes, perciben sus salarios de manos del tesorero general. Sigue lo abonado por la provisión de las villas: en la cuenta de Prado Güemes son 120.000 reales y, en la de Gómez de Terán, el monto se incrementa hasta los 176.990 reales como consecuencia del acuerdo firmado con la villa de las Navas del Marqués para la provisión de 18.000 varas de paño blanco anuales a 18 rls/vara ${ }^{34}$. El principal encargo de vestuario asignado se refiere a los nuevos batallones de marina que, por decisión de Verdes Montenegro, se aumentaban de ocho a diez. En la anterior cuenta de Prado Güemes existe una partida de 261.000 reales para este fin que se mantiene en nuestra cuenta con otros 50.000 reales destinados a concluir la contrata, «reglada de orden del señor Infante Almirante General» ${ }^{35}$. La provisión de la gente de marina iba a seguir sujeta a esta vía pues José Gallo recibió la Ro de 20/09/1743 para encargarse de "vestir la gente de Marina que servía en la escuadra que estaba en el Puerto de Toulon, como la que existía en los departamentos de Cádiz y El Ferrol». Debía preparar unos 2.000 vestidos, con paños de los almacenes, ajustando las necesidades de su provisión «con los sujetos que hallara más proporcionados» ${ }^{36}$. El tesorero pagaría a la recepción de los recibos de entrega firmados por Gallo así que, entre octubre y diciembre de 1743, fueron abonados $208.672,5$ reales por este concepto. Se incluye, además, los gastos de transporte que quedan por cuenta de la Real Hacienda ${ }^{37}$.

33. Idem.

34. La contrata completa podía alcanzar los 324.000 reales, con anticipación de 15.000 reales, pero parece que la villa solo pudo cumplir el encargo a medias.

35. AGS, DGT, inv. 16, guión 24, leg. 1, carp. 2.

36. Ibidem.

37. Ro de 28/05/1740 comunicada a Prado Güemes. La cuenta incluye más de setenta partidas por envíos ocurridos entre 1741 y la primera mitad de 1743 acordados con diferentes transportistas por un valor que oscila entre los 5 y los 7 reales por arroba transportada, a los que hay que añadir 3.000 reales de la contrata para el suministro de serajes y lías aprobada por Ro de 23/07/1741 en AGS, DGT, inv. 16, guión 24, leg. 1, carp. 2. 
En resumen, tras cancelar la disputa con la secretaría de Guerra de Montemar, Campillo se puso en manos de asentistas generales, catalanes en su mayor parte, para la provisión del vestuario de la tropa expedicionaria. Solamente puede matizarse esta afirmación con la idea de que procuró mantener vivo el deseo de fomentar los almacenes reales como alternativa, utilizándolos especialmente para la provisión de la marina. Es destacable asimismo considerar que no se puso en manos de un solo asentista sino que contrató a varios de ellos. Valparda y Florenza vistieron al ejército expedicionario, con la diferencia de que el primero y principal guarda una relación directa con el secretario de Hacienda, mientras que el segundo lo hace con el intendente de Cataluña. Simultáneamente, un pujante asentista de la Corte como López de Sedano veía incrementados sus encargos para abastecer la tropa estable en territorio peninsular. Se mantiene, además, la provisión diferenciada de las tropas de élite a través de Cebrián, Planell y los herederos de Lambari. La presencia de tantos asentistas en las cuentas del tesorero representa al menos la posibilidad de introducir cierta competencia entre ellos: de hecho, Planell mejoró a Cebrián en la provisión de alabarderos.

En relación con los valores, señalar que el año 1741 resultó mucho más económico que los dos posteriores de campaña, cuyos costes se elevan hasta los 6 millones de reales anuales. El coste de los uniformes oscila entre los 215 reales de la tropa regular de infantería, pasando por los 350-400 reales de caballería y dragones, hasta los 2.000 reales de guardias de corps o los 1.500 reales de alabarderos.

\subsection{La actuación de Ensenada en el sostenimiento de las campañas de Italia}

Durante su primera etapa del gobierno, Ensenada no tuvo otra prioridad que el mantenimiento de las tropas expedicionarias hasta el final de la guerra. No obstante, aunque la paz de Aquisgrán no estuvo suscrita hasta octubre de 1748, la intensidad del conflicto decayó antes, de modo que, a finales de 1747, comenzaba incluso a repatriarse parte de la tropa y a reducirse el tamaño del ejército expedicionario. Para comparar y apreciar matices y diferencias, hemos agregado en el mismo Cuadro $n^{\circ} 3$ los gastos por compra de vestuario incluidos en la segunda cuenta de Gómez de Terán y la primera de Horcasitas. 
Cuadro 3. Cuenta de los tesoreros generales José Gómez de Terán y Manuel Antonio de Horcasitas de lo abonado por vestuario (01/01/1744 - 31/12/1748)

\begin{tabular}{|l|r|r|r|}
\hline & \multicolumn{1}{|c|}{$(\mathrm{A})$} & \multicolumn{1}{c|}{$(\mathrm{B})$} & \multicolumn{1}{c|}{$\%$} \\
\hline A) Asentistas generales y pequeñas contratas & 17.511 .911 & 7.801 .962 & \multicolumn{1}{c|}{$86,6 \%$} \\
\hline Vicente Puyol (ejército expedicionario) & 11.795 .200 & 6.997 .480 & \\
\hline Matías de Valparda (ejército expedicionario) & 3.044 .303 & - & \\
\hline Matías de Valparda (guardias de corps y alabarderos) & 1.808 .880 & - & \\
\hline Mateo López Sedano & 431.822 & - & \\
Cristóbal Mestres y Baltasar Bacardi & 27.837 & & \\
\hline Pedro Geseli & - & 182.973 & \\
\hline Pequeñas contratas con proveedores & 403.869 & 621.509 & \\
\hline B) Almacenes de la Corte & 1.093 .168 & 1.057 .715 & $7,4 \%$ \\
\hline Contratos con las villas productoras de paños & 856.098 & 997.257 & \\
\hline Paños entregados en los almacenes de Madrid (Marina) & 104.031 & & \\
\hline Paños de Guadalajara entregados a Valparda & 47.461 & & \\
\hline Salario dependientes del almacén & 14.964 & 18.962 & \\
\hline Compras de estameña de Palencia (Marina) & 26.045 & & \\
\hline Conducción de vestuarios & 44.569 & 41.496 & \\
\hline C) De cuenta de los propios cuerpos & 684.024 & 549.742 & $4,2 \%$ \\
\hline D) Atrasos y gastos diversos & 512.381 & & $1,8 \%$ \\
\hline TOTAL & 19.801 .484 & 9.409 .419 & $100 \%$ \\
\hline
\end{tabular}

(A) $2^{a}$ cuenta de José Gómez de Terán (1/1/1744 - 31/1/1747)

(B) $1^{\text {a }}$ cuenta de Manuel Antonio de Horcasitas (1/2/1747 - 31/12/1748)

FUENTE: Elaboración propia sobre AGS, DGT, inv. 16, guión 24, leg. 1, carps. 3 y 4.

Cabe destacar que la distribución de porcentajes de recurso a los diversos sistemas de provisión es muy similar a los del cuadro $n^{\circ} 2$ (descontada la partida asignada a Montemar), con algún matiz relativo a un limitado pero creciente estímulo de los almacenes reales y la recuperación de la construcción del vestuario por cuenta de los regimientos. Las cifras absolutas destinadas a uniformar la tropa son asimismo representativas: si en la cuenta anterior se abonaron 14 millones de reales; en los años 1744, 1745 y 1746 (todos de campaña) el gasto se eleva hasta los 20 millones; y, en la cuenta de 1747 y 1748 (con escasa actividad bélica en el último) se reduce a 9,5 millones. Podemos estimar en consecuencia que el coste de cada año de campaña se sitúa en los 6-7 millones de reales (con 5 millones para 
el ejército expedicionario), reduciéndose dichos costes en 1741 y sobre todo en 1748. Si consideramos el precio medio de un uniforme de soldado regular alrededor de los 250 reales, constatamos que, efectivamente, podemos construir más de 25.000 uniformes anuales con este presupuesto, lo que nos permite cuadrar las cifras estimativas que expusimos al inicio del texto.

3.2.1. Como puede observarse, los asentistas generales percibieron 25 de los 29,5 millones del total abonado, con lo que lo principal ya está dicho. Sin embargo, conviene destacar que la provisión se concentra en un nuevo personaje, como es Vicente PuyOL, con dos terceras partes del total, un porcentaje muy superior al que manejaban Valparda y Florenza juntos. El propio Valparda reduce su participación en el suministro del ejército expedicionario hasta los 3 millones aunque se hace, a cambio, con la provisión de cuerpos de élite. Mateo López de Sedano pierde claramente posiciones en la nueva distribución de contratos que desarrolla Ensenada en virtud de sus preferencias. En este sentido, parece que el ministro se decantó completamente por la fórmula del proveedor único y monopolista personalizada por Puyol.

El arreglo de la provisión de Puyol comienza cuando, por Ro de 24/08/1744, se remite al nuevo intendente de Cataluña, marqués de Contamina, el pliego aprobado por SM presentado por Isidro Oriol de Barcelona para encargarse de la provisión del vestuario del ejército de Italia. Oriol pretendía sustituir simultáneamente a Valparda y a Florenza pues se obligaba, de entrada, a suministrar en tres meses y medio hasta 8.600 vestidos completos, con la supervisión de Contamina para ajustar los suministros y la actividad de los gremios «a la práctica y estilo que se observaba en aquel Principado en semejantes casos». El precio de cada uniforme de infantería sería de 187 reales, el de caballería de 335 reales, el de dragón de 383 reales y el de fusilero de 241 reales. La tercera parte del valor de los géneros se entregaría por vía de anticipación y en dinero efectivo en Barcelona, a través de su tesorería de Ejército (según el método de Florenza), descontando posteriormente en cada remesa la tercera parte del importe de lo entregado. Sin embargo, dos días más tarde el intendente recibe una real orden otorgándole facultad para recibir posturas sobre dicho asiento, a beneficio de la Real Hacienda, lo que nos alerta sobre la posibilidad de que alguien estuviera tratando de desplazar a Oriol. Efectivamente, no había terminado el mes de agosto cuando Vicente Puyol hacía baja de 10 reales por vestido de caballería, dragones y fusileros de montaña. Finalmente, la orden del intendente para que Puyol formalizase escrituras del nuevo asiento ante el escribano mayor Joseph Froch y cumpliera con el proceso de otorgamiento de fianzas, tiene fecha de 02/09/1744 ${ }^{38}$.

38. AGS, DGT, inv. 16, guión 24, leg. 1, carp. 3. 
La contrata se firmó por 8.600 vestidos trimestrales pero sabemos que esta sirve principalmente para definir las condiciones de la provisión. El número de uniformes y su destino se concreta mediante sucesivas órdenes que la Corona presenta al asentista. La primera es de 22/10/1744 mandándole fabricar 5.041 vestidos para el nuevo refuerzo de recluta enviado a Lombardía (1.916 vestidos para cuatro regimientos de infantería; 3.024 vestidos y 96 libreas para cuatro regimientos de caballería y cuatro de dragones). La Ro de 24/11/1744 le facultaba para que siguiera fabricando 20.000 vestidos necesarios para 28 batallones de infantería del Ejército de Saboya ${ }^{39}$. Por la Ro de 10/11/1744 se le encargan otros 675 vestidos para vestir, en su tránsito por Barcelona, a los escuadrones de caballería que pasaban a Italia. La Ro de 12/11/1744 mandaba completar los regimientos de infantería de Milán y Brabante con el medio vestuario devengado. La Ro de 18/11/1744 ordenaba complementar la anterior con libreas de trompetas y tambores, cartucheras de caballería y porta frascos de dragones. La RO de 17/12/1744 le encargaba otros 1.500 vestidos de fusileros; la de 01/01/1745, 200 vestidos para dragones de Extremadura; la de 09/01/1745 la composición exacta de las tropas de caballería y dragones del ejército de Italia que debían ser atendidas, incluyendo 4.116 soldados más 144 trompetas y tambores ${ }^{40}$. La Ro de 02/07/1745 mandaba entregar 1.105 uniformes del nuevo vestuario a cinco regimientos de caballería.

Como vemos, el asentista general debía estar preparado en definitiva para atender cualquier contingencia que la Corona tuviera a bien encargar, según las condiciones del contrato suscrito. Con cada entrega, el asentista recibía las certificaciones necesarias para presentarse ante el intendente y convenir ajustamientos temporales con la Real Hacienda. El primer ajustamiento concertado entre Puyol y Juan Martínez de Santesteban, tesorero del ejército de Cataluña, es de agosto de 1745 e incluye las entregas en el almacén de artillería aprobadas por los inspectores Argain y Ricardos, además del guarda almacén Bartolomé González de Estrada. Son 20 certificaciones firmadas entre noviembre de 1744 y agosto de 1745 cuyo total asciende a 4,5 millones de reales de vellón ${ }^{41}$. El segundo ajustamiento se formó el 04/12/1745 y fue por valor de 4,8 millones de reales incluyendo, además de la provisión de la recluta general de soldados de infantería de los 28 batallones, cinco nuevos encargos atendidos desde el final del último ajustamiento entre diciembre 1744 y noviembre de 1745. El tercer ajustamiento lo firma el nuevo tesorero de Cataluña Candas Inclán en octubre de 1746 e incluye una nueva contrata, firmada en agosto, y cinco recibos visados en el almacén provincial. Suma esta cuenta

39. Según estos datos, cada batallón lo forman 676 soldados y 14 tambores.

40. Cada regimiento de caballería está compuesto por 348 soldados y 8 tambores-trompetas; cada regimiento de dragones consta a su vez de 396 soldados y 18-17 tambores-trompetas.

41. Son 3.183.657 reales abonados por vía de anticipación (recibo de 24/12/1744) y 1.033 .360 reales a continuación del ajustamiento. 
1,8 millones de reales, de los que hubo que descontar el valor de los paños recibidos (353.459 reales según cálculo de Miguel de Ripa), así que quedaron líquidos 1,4 millones de reales. Como complemento a los anteriores, que son los principales, encontramos otros ajustamientos menores aunque todos juntos elevan su cuantía sobre el millón de reales. Alcanzamos de este modo los 11,8 millones de la cuenta de Puyol para el período 1744-1746 ${ }^{42}$.

No terminan aquí los costes del cuerpo expedicionario, pues Valparda suministró uniformes por valor de otros 3 millones de reales, aunque terminó de trabajar en 1746. No disponemos del mismo detalle en cuanto a sus provisiones, pero sabemos que recibió un millón de reales por el vestuario de regimientos de infantería, 277.371 reales por dragones y, sobre todo, un millón y medio por los regimientos de milicias desplazados a Italia. En definitiva, parece que Valparda sigue atendiendo la demanda del ejército expedicionario aunque completamente desplazado por Puyol de la primera línea de provisión. En todo caso, su participación eleva el coste de mantenimiento del ejército de Italia hasta los 5 millones de reales anuales que habíamos mencionado.

Por otra parte, también hemos comentado que Valparda sustituyó tanto a Cebrián como a Planell en el contrato de provisión de vestuario de guardias de corps y alabarderos. Su presupuesto es superior a los 1,8 millones de reales para estos pocos años. Esta circunstancia nos obliga a plantearnos la pregunta de qué contrato es más apetecido, el referido al suministro del ejército regular o el destinado a la provisión de 1.000 uniformes de soldados de élite con un coste equivalente al de 10.000 uniformes de tropa. No sabemos si estas razones influyeron en el intercambio de contratas o si se trata de una compensación a Valparda por la pérdida del cargo como proveedor principal de las tropas de Italia.

En la siguiente cuenta de Horcasitas para los años 1747 y 1748 tan solo aparece Vicente Puyol. La campaña de 1747 no tuvo la intensidad bélica de las anteriores, pero hubo que prepararla y dotarla económicamente; toda la provisión del vestuario se redujo entonces a una contrata de 7 millones de reales con Puyol. La datación y cuantía de los tres ajustamientos entre el asentista y el intendente son muy reveladores: el primero corresponde a agosto de 1747 y su valor es de 5,2 millones de reales por la construcción de 8.800 uniformes según las condiciones de la contrata de 1744; el segundo es del mes de enero de 1748 y su cuantía se reduce a «solamente» 2 millones de reales por 8.000 medios vestuarios para regimientos de infantería; el tercer y último ajustamiento es de diciembre de 1748 y 634.070 reales por concepto de ajustes de tipo contable y no por la entrega de materiales. La guerra había terminado en el año 1747; en 1748 ya no se sirvieron uniformes al ejército expedicionario y, por simpatía, a ningún otro cuerpo de ejército.

42. AGS, DGT, inv. 25, guión 1, leg. 17. 
En el cuadro $n^{\circ} 3$ aparecen asentistas menores. Destaca la continuidad de LÓPEZ DE Sedano, aunque muy desdibujada, pues simplemente mantuvo el encargo de concluir el vestuario pendiente de tropa de Marina y de vestir al regimiento de infantería de Lisboa (el gasto alcanzó los 300.000 reales). Se observa además la presencia de dos nuevos asentistas. El primer dato se refiere a una pequeña cantidad abonada por gastos relacionados con ejército de Saboya, pero resulta determinante para un futuro próximo, pues Cristóbal Mestres y BaLtasar BaCARDi se convertirán en la década de 1760 y 1770 en los más grandes asentistas de vestuario de todo el siglo $\mathrm{XVIII}^{43}$. El segundo dato se encuentra en la cuenta de Horcasitas y se refiere a un tal Pedro Geseli, del que no podemos dar noticia alguna, que aparece vistiendo a un regimiento de caballería de húsares. El caso es extraño, pues no se trata de tropas españolas y el asentista no volverá a aparecer en las cuentas, así que sospechamos se trata de un compromiso financiero puntualmente adquirido por la Corona en relación con el conflicto concluido.

3.2.2. Entre las fórmulas alternativas de provisión persiste el dominio de la actividad de los almacenes ReAles. Así, podemos señalar que el apartado referido a la provisión de las villas productoras de paños experimentó un apreciable incremento derivado de la extensión de la fórmula de contratación utilizada con las Navas del Marqués a otras villas. Con este fin se designa a Antonio Rodrigo, de las fábricas de Guadalajara, y a Francisco Javier Hidalgo, nuevo guarda almacén, como personas autorizadas para recibir paños y dar recibo de las entregas. La tesorería general pagaría a $19 \mathrm{rls} / \mathrm{vara}$ de paño blanco y las de color con cierto sobreprecio: la anticipación a las villas sería siempre de una mesada a descontar en la última entrega. La conducción a Madrid quedaba por cuenta de las fábricas, que gozaban no obstante de la franquicia de los derechos de tránsito y conservan el privilegio de quedar sus habitantes liberados de quintas y sorteos. En la cuenta de Gómez de Terán aparecen las cantidades abonadas a los municipios que se sumaron a la propuesta real; en total son 900.000 reales por tres años y cerca de 50.000 varas de paño ${ }^{44}$. En la cuenta de Horcasitas aparecen abonos por valor de un millón de reales pagados en dos años y 55.000 varas de paño entregadas, como testimonio de una tendencia de signo creciente ${ }^{45}$. Los salarios abonados a dependientes y gastos de transporte de los almacenes generales confirman la importancia de una

43. Véase SOlbes Ferri, op. cit., 2012, pp. 287-88.

44. Ciudad de Teruel (226.537 reales) y las villas de las Navas del Marqués (143.756), Villoslada (125.553), Lumbreras (113.800), Anguiano (84.682), Pedroso (66.956) y Cabeza de Buey (94.814). AGS, DGT, inv. 25, guión 1, leg. 17.

45. Villas de Navas del Marqués (389.234), Villoslada (244.296), Cabeza de Buey (154.293), Pedroso (91.732), Anguiano (84.719) y Olmeda y Nuevo Baztán (32.984). AGS, DGT, inv. 25, guión 1, leg. 17. 
actividad fuertemente potenciada por la Corona. La cuenta de Gómez de Terán indica, además, que el destino de estos géneros fue la conclusión del vestuario de la Marina encargado por Campillo o la entrega de géneros a Valparda para el suministro del regimiento de Portugal, tras preceptiva real orden.

El apartado referido a vestuarios construidos DE CUENTA DE LOS PROPIOS CUERPOS también presenta una fuerte recuperación que guarda una relación cada vez más estrecha con los almacenes reales. Con Gómez de Terán recurrieron a este método, por orden de importancia, algunos regimientos de caballería (340.487 reales), de artillería (272.310 reales), de infantería de la Reina (86.632 reales) o de fusileros de montaña de Parma (52.670 reales), además de pequeñas partidas destinadas a infantería (17.432 reales) e inválidos (1.125 reales). El conjunto se eleva hasta los 700.000 reales en tres años. Lo interesante es que durante el tiempo de Horcasitas las cantidades aumentaron hasta los 550.000 reales abonados en dos años, pues utilizaron este método las reales guardias (281.196), el regimiento de infantería de Cantabria (180.646 reales) y otros regimientos de infantería ( 87.900 reales). Lo que resulta novedoso es que, en muchos casos, los regimientos autorizados para suministrarse de su cuenta, acudieron a los almacenes reales en busca de las provisiones necesarias. De este modo se produce una interesante vinculación entre dos formas distintas de provisión, aunque las diferencias persisten, porque una cosa es que el oficial habilitado de un regimiento acuda con su dinero a los almacenes y otra que la Corona decida encargar a los almacenes la construcción de unos uniformes en concreto. En todo caso, cabe concluir que Ensenada no muestra el rechazo a esta alternativa que mostró Campillo, quizá porque la presión de los militares y de la secretaría de Guerra ya no fuera por entonces tan intensa.

La provisión a través de CONTRATAS DIRECTAS también se reactiva en pequeña escala. Podemos dedicar unas pocas líneas para constatar que encontramos, por ejemplo, 50.000 reales abonados a un tintorero, un sastre y un maestro espartero que guardan relación con los almacenes de Madrid y, por otra, un encargo de sillas de montar al gremio de silleros, latoneros y freneros de Barcelona, bolsas y cinturones de ante o un sastre llamado Ramón Puyol -desconocemos si guarda parentesco con Vicente Puyol- encargado de fabricar uniformes de prisioneros, con un coste aproximado de 350.000 reales y relacionado a su vez con los almacenes de Barcelona. En la cuenta de Horcasitas esta forma de contratación también experimenta un claro repunte, concentrado en Barcelona. Vuelve a aparecer Ramón Puyol con un importante encargo para el arreglo de uniformes (182.735 reales), el mismo gremio de silleros de Barcelona (289.286 reales), un zapatero llamado Francisco Villajuana que percibe 140.000 reales por su trabajo y el encargo de unos capotes para los cuerpos de guardia (6.750 reales). Como vemos las cantidades asignadas a la contratación directa ya no son despreciables. 
Concluimos con el apartado referido a ATRAsos que aparece en la cuenta de Gómez de Terán y que no tiene otra trascendencia sino la de exponer los fallos habidos en el sistema de provisión del ejército expedicionario, corregidos en la cuenta de Horcasitas. El más significativo es el abono al regimiento de milicias de Murcia que fue enviado a participar en las campañas italianas construyendo los uniformes de su cuenta, pero que no los pudo cobrar hasta 1746 cuando ya había quedado extinguido. El resto son gastos puntuales para financiar la vestimenta de alguna recluta o ajustes en abonos a proveedores.

Estos sistemas de provisión alternativos al recurso a asentistas vuelven a destacar, más que por su valor, por lo que significan en sí mismos y su principal efecto es el de obligarnos a matizar la idea del monopolio absoluto en la provisión de asentistas. Todos ellos comienzan a enlazarse, de un modo u otro, con los almacenes de Madrid o de Barcelona: los regimientos que se visten de su cuenta recurren a ellos, utilizan los paños de las villas, gestionan contratas directas de la secretaría de Hacienda, etc. Aunque de modo muy restringido, estos almacenes se convierten en la única y verdadera alternativa al monopolio absoluto del asentista general. Porque, efectivamente, el principal efecto de las gestiones ministeriales es que contribuyeron a consolidar el monopolio de un solo proveedor, con todas sus consecuencias. La Corona simplifica la gestión administrativa (que, como hemos podido constatar a lo largo de este estudio, resulta ciertamente compleja) y adquiere mayor control sobre un intermediario completamente dependiente de sus demandas. El asentista evita como compensación la competencia del resto de proveedores y se garantiza la atención exclusiva a una elevada demanda.

\section{Conclusiones}

Nuestra principal conclusión es que existe una clara y absoluta continuidad en el sistema de provisión de vestuario del Ejército español entre las fechas posteriores a la muerte de Patiño y la década de 1740. Campillo y Ensenada pudieron concentrar sus energías en alcanzar su propósito de suprimir a los arrendadores generales pero no pudieron, o no quisieron, librarse de los asentistas. Campillo mantuvo incluso a los mismos asentistas (Valparda y Cebrián) mientras que Ensenada concentró aún más la provisión en manos de uno nuevo como es Vicente Puyol. En este sentido, encontramos más continuidad con las viejas prácticas de gestión de las previstas. La principal diferencia para los asentistas es que, al administrarse directamente las rentas reales, ya no podían combinar la contratación de asientos con el arriendo de rentas para asegurar los abonos en el caso de impago por parte de la Corona. Tendrían que esperar, como cualquier proveedor, a negociar sus ajustamientos con la tesorería general y percibir en consecuencia las correspondientes cartas de 
pago. La compensación pasa por la concentración monopolística de la provisión, algo que parece cumplirse punto por punto en nuestra exposición.

La segunda conclusión es que el sistema de provisión y financiación de la compra de vestuario funcionó con corrección, regularidad e incluso cierta eficacia. Las cifras ofrecidas, puestas en relación con el valor medio de los uniformes, nos permiten validar la idea de la construcción de unos 25.000 uniformes anuales para renovar el vestuario de todo el Ejército español cada cuatro años, tal y como estaba dispuesto. El objetivo de concentrar el control contable en manos de la secretaría de Hacienda, a través de la tesorería general, es asimismo una realidad. La demanda y contratación del suministro se ejecuta con agilidad y los acreedores de la Real Hacienda reciben puntualmente sus cartas de pago. Solo nos resta comprobar que dichas cartas de pago se abonaron puntualmente por la tesorería, pero tenemos la sensación de que el descontrol de la etapa anterior está muy lejos de ofrecerse en estos años. Resulta evidente que, en el caso de atrasos o impagos acumulados, esta circunstancia se vislumbraría de algún modo en nuestra documentación, cosa que no sucede.

La tercera conclusión es que la construcción del vestuario del ejército y buena parte de su financiación se concentra claramente en Cataluña. Este es el motivo por el que ninguno de los asentistas de vestuario aparecía relacionado hasta ahora con unos financieros navarros mucho mejor estudiados por la historiografía. No parece esta una solución caprichosa sino la combinación de tres realidades: desde el final de la guerra de Sucesión el mayor número de cuerpos del ejército español se concentra en el Principado; los cuerpos expedicionarios parten de la Ciudad Condal con destino a Italia, tanto por vía terrestre como marítima; $y$, por último, toda Cataluña en general, y Barcelona en particular, son herederas de una significativa tradición textil que la demanda de la Corona contribuiría sin duda a potenciar. Nos ha sorprendido constatar la realidad de la ejecución de los antiguos deseos de Patiño desarrollada por los intendentes de Cataluña, en relación directa con la tesorería de Ejército de Cataluña a través de su contador y tesorero. La extensión del control de caudales por parte de la tesorería general hacia un nivel territorial a través de las tesorerías de ejército era una realidad confirmada para la segunda mitad del siglo XviII, pero nuestro análisis registra que esta relación es un hecho en fechas anteriores.

Habría que destacar, por último, que, aún con la preponderancia absoluta de los asentistas, el sistema de provisión alternativo a través de los almacenes reales pervive durante estos años e incluso parece que tiende a potenciarse durante el gobierno de Ensenada. Dicho sistema se ordena alrededor de la gestión de los empleados de los almacenes para la provisión de paños por parte de las villas próximas a la Corte, la elaboración de los uniformes por parte de los gremios madrileños y la asignación del vestuario a determinados cuerpos por real orden. 
Más caprichosa resulta, a nuestro entender, esta segunda vía de provisión puesto que, aunque podríamos considerar la presencia permanente de tropas y cuerpos de élite en la Corte como argumento para su estímulo, la realidad es que el destino final de los uniformes no fueron esos cuerpos sino otros como los batallones de la marina. Así que, en este caso, los uniformes podrían haber sido construidos en cualquier otro territorio con una mayor tradición dentro de esta actividad textil.

\section{A MOdO DE COLOFÓN}

Necesitamos añadir un nuevo epígrafe a nuestro texto para evitar uno de los errores más comunes en nuestro oficio de historiadores como es el de dar un sentido finalista a nuestros análisis. Si lo concluyéramos en este punto, tendríamos que considerar a Ensenada como un ministro que apostó decididamente por un sistema de provisión de vestuario dominado por el recurso a asentistas. Podríamos incluso considerar que Ensenada estaba razonablemente satisfecho con el control administrativo y contable de la provisión ejercido por la secretaría de Hacienda. Pues bien, es este nuestro caso un claro ejemplo de la necesidad de analizar con perspectiva y no dejarnos influir por argumentos de orden cambiante. Nada mejor para concluir nuestro estudio, a la espera de subsiguientes análisis, que exponer el contenido de la Ro de 24/08/1749 que establece para ese año la nueva regla de provisión del vestuario de los ejércitos retornados desde Italia.

Deseando el Rey que sus tropas estén asistidas puntualmente con el vestuario, entero y medio, por las reglas que más se adapten al intento de que los jefes de los Cuerpos sean responsables de ese cuidado. Ha resuelto que de su cuenta se libren con el prest a cada regimiento de Infantería de dos batallones 6.080 reales y 8 maravedíes y un tercio de otro en cada mes; por cuyo prorrateo recibirá, al fin de los cuarenta [meses] que ha de durar cada vestuario, el importe de 243.209 reales y 22 maravedíes de vellón que, sobre el actual pie, se considera [el valor] para el [vestuario] entero y medio. A cada regimiento de Caballería de los que tienen su vestuario blanco se ha de abonar por la misma regla en cada mes 2.493 reales de vellón. Y al que [lo tiene] de dos colores (...) 2.639 reales y 5 maravedíes. A cada uno de los de Dragones 2.395 reales y 8 maravedíes también mensuales ${ }^{46}$.

De un plumazo Ensenada está terminando con Puyol, con Valparda..., e incluso con los almacenes generales. Las tropas regulares, a las que afecta la orden, han vuelto a sus cuarteles peninsulares, se ha firmado la paz y el número de sus unidades se ha visto reducido en una tercera parte. A partir de ahora, van a ser los propios oficiales de los regimientos los encargados de construir los vestuarios con

46. AGS, DGT, inv. 25, guión 1, leg. 17. 
un dinero que habrán recibido previamente con el haber mensual de los soldados anotados en la revista. Obviamente necesitan ir separando este dinero para crear un fondo, llamado Gran Masa, que, al cumplirse los cuarenta meses, debe ser suficiente para financiar la renovación del vestuario amortizado. Solo permanecen reguladas según el sistema tradicional de asientos las tropas de élite, las de marina y las de África, cuyos contratos de abastecimiento se convertirán en herencia disputada por los antiguos asentistas.

La Corona había vuelto a cambiar las reglas del juego, en expresión afortunada de Torres Sánchez. Todo el sistema de provisión descrito en este estudio no parece que fuera en realidad del gusto de Ensenada. El ministro tenía otros planes y, en cuanto la guerra le dio la oportunidad, procedió a aplicarlos con su habitual decisión. Esta circunstancia puede guardar relación, ahora sí, con la mencionada supresión de arrendadores de rentas e imposición de la administración directa de rentas.

De modo que debemos introducir una última conclusión, que debe necesariamente referirse a la necesidad de considerar que las conclusiones anteriores deben quedar exclusivamente circunscritas al período de tiempo analizado en este trabajo.

\section{BibliografíA}

Andújar Castillo, F.: «Elites de poder militar: las Guardias Reales en el siglo xvin», en Castellano, J. L., Dedieu, J. P. y López Cordón, Ma V. (eds.): La pluma, la mitra y la espada. Estudios de historia institucional en la Edad Moderna, Madrid, 2000, pp. 65-94.

— : «La Corte y los militares en el siglo XviII», en Estudis, 27 (2001), pp. 91-120.

— : «La reforma militar en el reinado de Felipe V», en Pereira Iglesias, J. L. (coord.): Felipe de Borbón, 1701-1743, Córdoba, 2002, pp. 615-640.

- : «La "reforma” militar del Marqués de la Ensenada», en Guimerá Ravina, A. y Peralta Ruiz, V. (coords.): El equilibrio de los imperios: de Utrecht y Trafalgar, vol. 2, 2005, pp. 519-536.

Aquerreta GonzÁlez, S.: «La participación de los financieros nacionales en la Guerra de Sucesión: el abastecimiento de víveres al Ejército», en Torres SÁnchez, R. (coord.): Capitalismo mercantil en la España del siglo XVIII, Pamplona: EUNSA, 2000, pp. 273-314.

- : «La Casa de Arizcun 1725-1742: las estrategias financieras de un hombre de negocios en el Madrid de la Ilustración», en Serrano Martín, E.; Sarasa Sánchez, E. y Ferrer Benimeli, J. A. (dirs.): El Conde de Aranda y su tiempo, Madrid: Institución Fernando el Católico, vol. 1, 2000, pp. 659-678.

- Negocios y finanzas en el siglo XVIII: la familia Goyeneche, Pamplona: EUNSA, 2001.

Aquerreta, S. (coord.): Francisco Mendinueta: finanzas y mecenazgo en la España del siglo XVIII, Pamplona: EUNSA, 2002. 
Caro Baroja, J.: La Hora Navarra Del xviII: (Personas, Familias, Negocios e Ideas), Pamplona: Institución Príncipe de Viana, 1985.

Casado Rabanal, D.: La marina ilustrada. Sueño y ambición de la España del siglo XVIII. Desarrollo y crisis (1702-1805), Madrid: Ministerio de Defensa, 2009.

Cervera Pery, J.: La Marina de la Ilustración (resurgimiento y crisis del poder naval), Madrid: San Martín, 1986.

Delgado Barrado, J. M.: Aquiles y Teseos. Bosquejos del reformismo borbónico, 17011759, Universidad de Granada, 2007.

Dubet, A.: «¿Tesorería Mayor o Tesorería General? El control contable en los años 1720: una historia conflictiva», en De Computis, 13 (2010), pp. 95-132.

- : «José Patiño y el control de la Hacienda. ¿Una cultura administrativa nueva?» en López Díaz, M. (ed.): Élites y poder en las monarquías ibéricas: del siglo XVII al primer liberalismo. Editorial Biblioteca Nueva: Madrid, 2013, pp. 39-56.

Fernández Albadalejo, P.: «El decreto de suspensión de pagos de 1739: análisis e implicaciones» en Moneda y crédito, no 142 (1977), pp. 64-69.

Gómez Ruiz, M. y Alonso Juanola, V.: El Ejército de los Borbones: reinados de Felipe Vy Luis I (1700-1746), Madrid, 1989.

Gómez URdánez, J. L.: El proyecto reformista de Ensenada, Editorial Milenio, 1996.

GonzÁlez Enciso, A.: «La promoción industrial en la España Moderna: intervención pública e iniciativa privada», en Riвot García, L. A. y DE RosA, L. (dirs.): Industria y Época Moderna, Actas, Madrid, 2000, pp. 15-46.

- : "Las finanzas reales y los hombres de negocios en el siglo XviII», en Dubet, A. (coord.): Administrer les finances royales dans la monarchie espagnole (xvie-XIXe siècles), Rennes: Presses Universitaires, 2008, pp. 227-241.

- : «Buying cannons outside: when, why, how many? The supplying of foreign iron cannons for the Spanish Navy in eighteenth century», en HaRding, R. y SolbeS FERri, S. (eds.): The Contractor State and Its Implications, 1659-1815, Universidad de Las Palmas, 2011, pp. 135-158.

—-: «La guerra de la Oreja de Jenkins. Política y economía», en Díaz Benítez, J. J., Galván Rodríguez, E. y Luxán Meléndez, S. de: Conflictos bélicos y relaciones internacionales (1739-1927), Ediciones Idea: Santa Cruz de Tenerife, 2012, pp. 29-87.

- (coord.): Navarros en la Monarquía Española en el siglo XVIII. Pamplona: EUNSA, 2007.

Hernández Escayola, Ma C.: Negocio y servicio: finanzas públicas y bombres de negocios en Navarra en la primera mitad del siglo XVIII, Pamplona: EUNSA, 2004.

Kamen, H.: La Guerra de Sucesión en España, 1700-1715, Grijalbo; Barcelona, 1974, pp. 75-83.

Ozanam, D.: «Historia de España», Menéndez Pidal, J. Ma y Jover Zamora (dir.). T. XXIX: La época de los primeros Borbones, 1, 1700-1759, 1985, pp. 562-64.

Perona Tomás, D. A.: La Secretaría de Estado y del Despacho de Marina. La institución $y$ los hombres (1714-1808), Universidad de Murcia, 1995.

Rodríguez Garraza, R.: «Asentistas navarros durante la Guerra de Sucesión (17051711)», en Enciso Recio, L. M.: La burguesía española en la Edad Moderna, vol. II, Valladolid: Universidad de Valladolid, 1996, pp. 725-752. 